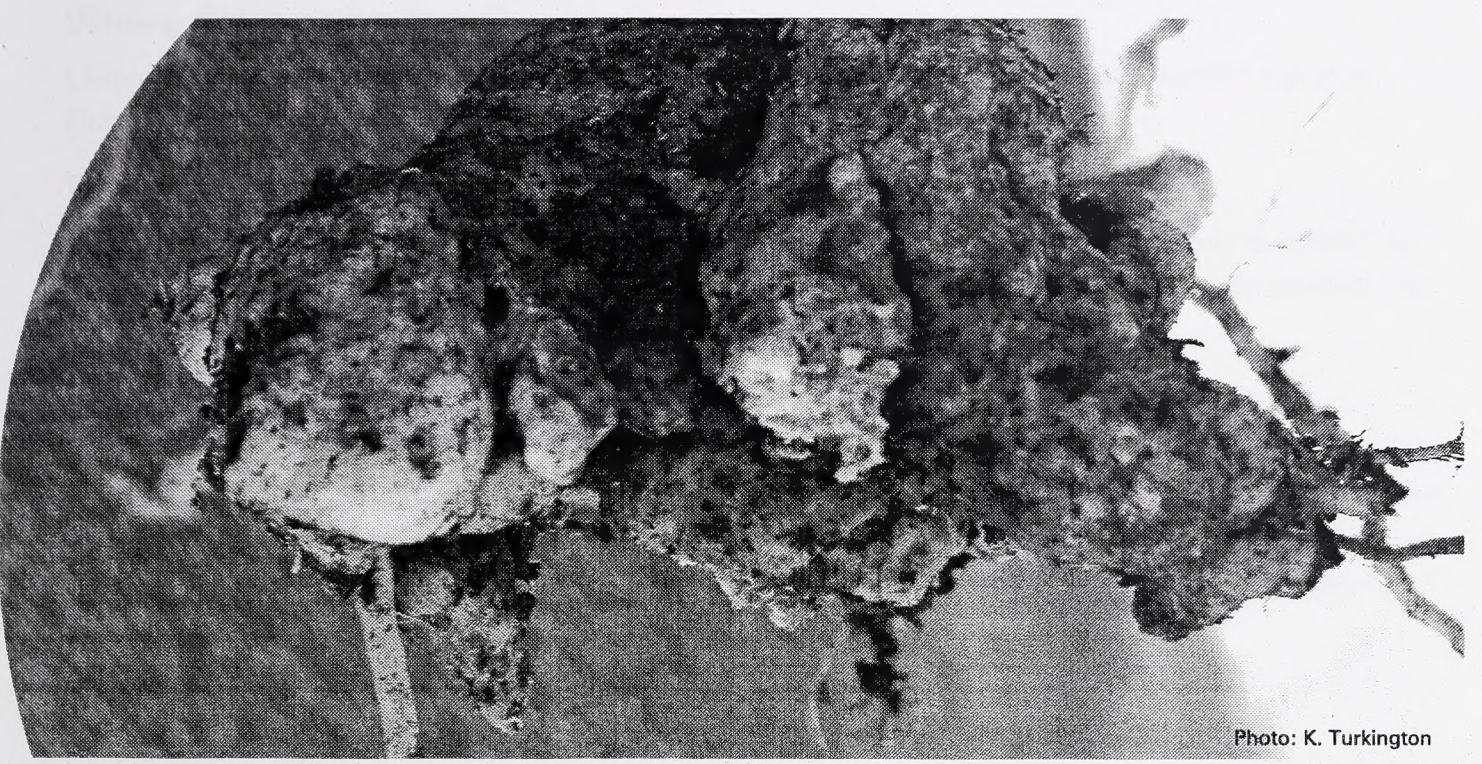

\title{
Alberta Clubroot Management Plan
}

Developed by:

Alberta Clubroot Management Committee

June 2007 



\section{Clubroot Overview}

\section{What is it?}

Clubroot, caused by Plasmodiophora brassicae, is a serious disease of canola, mustard and other crops in the cabbage family. Cole crops such as broccoli, brussels sprouts, cabbage, cauliflower, Chinese cabbage, kale, kohlrabi, radish, rutabaga and turnip are also susceptible to clubroot.

\section{Where did it come from?}

Clubroot was first detected in a canola field near Edmonton in 2003. This find was the first report of clubroot on canola in Canada. How the disease made its way to Alberta is unknown.

\section{Why has it spread?}

Clubroot can only spread through resting spores in the soil. Resting spores are most likely to spread via contaminated soil carried from field to field by equipment. Tillage equipment represents the greatest risk of spreading the disease as soil is frequently carried on shovels from field to field.

\section{Why is it of concern?}

Resting spores are extremely long lived, surviving in soil for up to 20 years. The longevity of the resting spores is a key factor contributing to the seriousness of the disease, especially under tight canola rotations. Research indicates that infestations nearing 100 per cent cause about 50 per cent yield loss, while infestations of 10 to 20 per cent lead to 5 to 10 per cent yield loss. Also, yield and quality (oil content) of the seed are reduced.

\section{What is being done about it?}

In spring 2007, clubroot was added as a declared pest to Alberta's Agricultural Pests Act. The Agricultural Pests Act is the legislative authority for enforcement of control measures for declared pests in Alberta. Researchers from the University of Alberta and Alberta Agriculture and Food have begun research projects on clubroot in Alberta.

\section{What is the current state of clubroot in Alberta?}

At this time, clubroot has primarily been found in the Edmonton area. However, it has the potential to spread to most of the traditional canola growing areas of Alberta.

\section{Background}

Clubroot is a serious soil-borne disease of cruciferous crops (canola and cabbage family) worldwide and was first identified in Europe in the thirteenth century. This disease is a major problem in cole crops (cruciferous vegetables like cabbage) in some areas of British Columbia, Quebec and Ontario. There have been two previous reports of clubroot in cole crops in Alberta. Thus, clubroot is not a new disease in Canada or Alberta. 
However in 2003, the first report of clubroot in western Canada was confirmed in several canola fields near Edmonton. Clubroot has continued to be found primarily in the Edmonton area, mainly in the surrounding counties of Sturgeon, Parkland, Leduc and Strathcona.

Clubroot can affect broccoli, brussels sprouts, cabbage, cauliflower, Chinese cabbage, kale, kohlrabi, radish, rutabaga and turnip. Canola/rapeseed and mustard are also susceptible to this disease. There are several non-cruciferous weak hosts, but their contribution to disease development and carryover is not well known.

Symptoms will vary depending on the growth stage of the crop when infection occurs. Early infection at the seedling stage can result in wilting, stunting and yellowing of canola plants in the late rosette to early podding stage.

Infection that occurs at later stages may not show plant wilting, stunting or yellowing. However, infected plants will ripen prematurely, and seeds will shrivel. Thus yield and quality (oil content) are reduced. In such cases, plants should be pulled from the soil to check for gall formation on roots.

Swedish researchers found that infestations nearing 100 per cent caused about 50 per cent yield loss, while infestations of 10 to 20 per cent led to 5 to 10 per cent yield loss. These levels are similar to sclerotinia stem rot infection in canola where a general rule of thumb is that yield loss is half of the percentage of infected stems. This comparison is a reasonable one since both diseases restrict the flow of water and nutrients to developing seeds.

\section{Objective}

\section{Minimize the spread and build-up of clubroot in canola, mustard and market garden fields in Alberta.}

\section{Regulatory Status}

Alberta's Agricultural Pests Act is the legislative authority for enforcement of control measures for declared pests in Alberta. Clubroot was added as a declared pest to the Agricultural Pests Act in April 2007. The Minister of Alberta Agriculture and Food is responsible for this Act. However, enforcement is the responsibility of the municipality.

Pest inspectors may be appointed by the local municipality or by the Minister of Agriculture and Food. By virtue of the office, an Agricultural Fieldman is a pest inspector under the Agricultural Pests Act. Pest inspectors have the power to enter land at a reasonable hour, without permission, to inspect for pests and collect samples. 
Enforcement of pest control measures is the responsibility of the municipal authority; Agricultural Fieldmen are responsible for enforcing pest control measures in their municipality.

The owner or occupant of land has the responsibility of taking measures to prevent the establishment of any pest on land, property and livestock and to control or destroy all pests on the land or property.

Control measures for clubroot are specified in this management plan. It is important to understand that these control measures represent an acceptable standard that is to be applied in all municipalities across the province. Municipalities can enhance the standard within their own jurisdictions.

\section{Risk of the Spread of Clubroot in Alberta}

Resting spores are most likely to spread via contaminated soil carried from field to field by equipment. Tillage equipment represents the greatest risk of spreading the disease as soil is frequently carried on shovels from field to field. Other methods of spread could include movement of soil with water or wind, soil attached to seed (earth tag) and soil on hay, straw or greenfeed.

Resting spores are extremely long lived, with a half-life of about four years, but surviving in soil for up to 20 years. The longevity of the resting spores is a key factor contributing to the seriousness of the disease, especially under tight canola rotations.

Growers and land users (surveyors, seismic operators, recreationalists, etc.) need to be vigilant and diligent in removing potentially contaminated soil from equipment prior to leaving fields, to prevent the introduction of clubroot to clean fields because few economically viable options currently exist to control infestations in canola.

\section{Management Plan Rationale}

The most desirable approach to managing clubroot in Alberta is through a proactive program designed to prevent the spread of this pathogen in the province. The program will include both a management and a communication plan. The long-term goal of this management plan is to prevent the establishment and minimize the spread of clubroot in Alberta. 


\section{Management of Clubroot}

1. Use long rotations between canola crops - four years or more. Although this method will not prevent the introduction of clubroot to clean fields, it will restrict disease development within the field and probably avert a severe infestation. As well, it will limit the risk of other canola diseases such as blackleg and fusarium wilt.

2. Practice good sanitation to restrict the movement of potentially contaminated soil. This approach will also help reduce the spread of other diseases, insects and weed seeds. The resting spores are most likely to spread via contaminated soil. Thus, producers should follow the practice of cleaning soil and crop debris from field equipment before transport from all fields. Cleaning equipment involves knocking or scraping off soil lumps and sweeping off loose soil.

- For risk averse producers, additional cleaning steps will slightly decrease the risk of infection, but will involve considerably more work and expense:

- After removal of soil lumps, wash equipment with a power washer, preferably with hot water or steam.

- Finish by misting equipment with weak disinfectant (1-2\% active ingredient bleach solution). Use of a disinfectant without first removing soil is not recommended as soil inactivates most disinfectants.

3. Use direct seeding and other soil conservation practices to reduce erosion. Reducing the amount of tillage on any given field will reduce the spread of the organism within the field and to other fields. Resting spores can also readily move in soil transported by wind or water erosion.

4. Scout canola fields regularly and carefully. Identify causes of wilting, stunting, yellowing and premature ripening - do not assume anything!

5. Avoid the use of straw, hay or greenfeed, silage and manure from infested or suspicious areas. Clubroot spores may survive through the digestive tracts of livestock.

6. Avoid common untreated seed, including canola, cereals and pulses. Earth tag on seed from infested fields could introduce resting spores to clean fields. Seed treatment fungicides appear to control spores on seed with contaminated soil, but this area needs further research to confirm.

The risk of spreading clubroot through contaminated seed or plant material is much less than through transporting contaminated soil on field equipment. 


\section{Responsibilities}

\section{Alberta Agriculture and Food (AF)}

- Pest Management Branch (PMB) of AF will do the following:

- co-ordinate the Alberta Clubroot Management Plan

- provide regulatory consultation and training

- prepare and provide technical information on clubroot control recommendations to inspectors and others in the field

- assist in educating the agriculture industry, oil industry and general public about clubroot and the threat that it represents to Alberta

- inform other industry sources such as the agricultural retail industry environmental companies, custom applicators, landscaping companies on the movement of soil on equipment within the municipalities

- develop a communication plan to inform all stakeholders about the threat of clubroot

\section{Agricultural Service Boards (ASB)}

- Provide support and resources to the Agricultural Fieldmen in carrying out their duties.

- Agricultural Fieldmen will actively monitor their municipality for clubroot and do the following:

- provide recommendations and information to farmers on clubroot prevention and management

- enforce control measures as necessary to meet the objectives of the Alberta Clubroot Management Plan

- maintain records of infestations

- assist in educating the Alberta agriculture industry about clubroot and the threat that it represents to Alberta

\section{Landowners/Occupants}

- take measures to prevent the establishment of clubroot on their land and to minimize the spread of clubroot to other land or property

- observe and practice all management practices to meet the objectives of the Alberta Clubroot Management Plan

\section{Agricultural Retail Industry (pesticides, fertilizer, etc)}

- take measures to prevent the establishment of clubroot and to minimize the spread of clubroot to other land and property

- assist in educating the Alberta agriculture industry about clubroot and the threat it represents to Alberta 


\section{Custom Equipment Operators}

- take measures to prevent the establishment and to minimize the spread of clubroot on the land and property

- assist in educating the Alberta agriculture industry about clubroot and the threat it represents to Alberta

Oilfield, Gas and Other Companies (operating on agricultural land)

- take measures to prevent the establishment and to minimize the spread of clubroot on the land and property

- assist in educating Alberta's oil, gas and other related industries about clubroot and the threat it represents to agriculture in Alberta

\section{Clubroot Management Committee}

- provides a forum to represent the interests and views of the Alberta agriculture industry regarding the management of clubroot

- recommends management strategies for clubroot for inclusion in the Alberta Clubroot Management Plan

- assists in educating the Alberta agriculture industry about Clubroot and the threat that it represents to Alberta

- evaluates the Alberta Clubroot Management Plan as required

\section{Suggested References}

Clubroot Disease of Canola and Mustard factsheet, Agdex 140/638-1, Alberta Agriculture and Food

Clubroot of Crucifers Control Strategies, Agriculture and Agri-Food Canada, Horticulture 


\section{Clubroot Management Committee Contact List}

Paul Laflamme - Chair

Alberta Agriculture and Food

paul.laflamme@gov.ab.ca

\section{Brent Hoyland}

Flagstaff County

bhoyland@flagstaff.ab.ca

\section{Dave Sidlick}

Sturgeon County

dsidlick@sturgeoncounty.ab.ca

\section{Ward Toma}

Alberta Canola Producers Commission

ward.toma@canola.ab.ca

\section{John Mayko}

Canola Council of Canada

maykoj@canola-council.org

\section{Don Christensen}

AB Farm Fresh Producers Association dlchrist@mcsnet.ca

\section{Emile deMilliano}

Agricore United

edemilliano@agricoreunited.com

\section{Chad Jarvis}

Cargill

chad jarvis@cargill.com

\section{Ron Howard}

Alberta Agriculture and Food

ron.howard@gov.ab.ca

\author{
Sheau-Fang Hwang \\ Alberta Agriculture and Food \\ sheau-fang.hwang@gov.ab.ca \\ Steve Strelkov \\ University of Alberta \\ stephen.strelkov@ualberta.ca \\ Ralph Lange \\ Alberta Research Council \\ ralph@arc.ab.ca \\ Murray Hartman \\ Alberta Agriculture and Food \\ murray.hartman@gov.ab.ca \\ Clifford Goerz \\ Parkland County ASB \\ cgoerz@parklandcounty.com
}


Digitized by the Internet Archive in 2017 with funding from University of Alberta Libraries

https://archive.org/details/albertaclubrootm00albe_1 
